\title{
Impact of graphite admixture on electrical properties of alkali-activated slag mortars
}

\author{
Ivo Kusak ${ }^{1, *}$, Miroslav Lunak $^{1}$ and Pavel Rovnanik ${ }^{2}$ \\ ${ }^{1}$ Institute of Physics, Faculty of Civil Engineering, Brno University of Technology, Veveři 95 , \\ 60200 Brno, Czech Republic \\ ${ }^{2}$ Institute of Chemistry, Faculty of Civil Engineering, Brno University of Technology, Veveří 95, \\ 60200 Brno, Czech Republic
}

\begin{abstract}
One of the objectives of the applied research's striving consists in providing the users with new slag-mortar-based materials. Basic research, in its turn, aims at examining the newly created materials from the viewpoint of all possible testing methods. Slag mortar specimens were subjected to electrical analysis carried out by means of an $\mathrm{ZNC}$ vector analyser and an SPEAG-made DAK-12 coaxial probe within the frequency range from $100 \mathrm{MHz}$ to $3 \mathrm{GHz}$ and, furthermore, a dedicated automatically measuring device within the frequency range from $40 \mathrm{~Hz}$ to $1 \mathrm{MHz}$. The frequency spectra of interest were measured on various copolymer specimens differing from each other by the content of the carbon powder. Higher graphite powder content increases the electrical conductivity of cement/slag-based building materials, which thus become easier to measure by means of electromagnetic measuring methods. Carbon admixture may also improve the material's antistatic properties.
\end{abstract}

\section{Introduction}

The development of alkali-activated slag (AAS) cements has been object of intensive research recently [1]. The AAS cements are manufactured by mixing fine-ground glass slag with strong alkaline solutions, such as water glass $\mathrm{NaOH}$ and $\mathrm{Na}_{2} \mathrm{CO}_{3}$. As far as their mechanical properties are concerned, the AAS cements are comparable with the PC (Portland cement), particularly in the case where water glass is used as activator. They also feature better endurance, better resistance against aggressive environment, better frost resistance and lower amount of hydration heat released. Among their most important drawbacks, there are the high autogenous as well as dry-up-related shrinkage, which is particularly characteristic for activators in the form of water glass. If $\mathrm{NaOH}$ and $\mathrm{Na}_{2} \mathrm{CO}_{3}$ are used, they show similar shrinkage as the PC. Among other drawbacks there are their propensity to form efflorescences and, in some cases, to too fast setting [2,3].

To enhance the applicability of electrical measuring methods, graphite powder appears to be a convenient admixture, increasing the electrical conductivity of the bodies under test. Thus obtained increased electrical conductivity will enhance the measurability and provide for better utilization of the impedance spectroscopy method. The amount of the graphite

*Corresponding author: kusak.i@,fce.vutbr.cz 
powder admixture is of the order of several per cent of the specimen total weight. Attainment of the so-called percolation threshold could be detected by the measurement $[4,5]$.

\section{Experiment setup}

Following brands of input raw materials were used for the specimen preparation: SMŠ 380 granulated blast-furnace slag, SUSIL MP 2.0 dried water glass, PG1-3 sand, COND 896 powdered graphite, Triton X-100 nonionic detergent, Lukosan S.defoamer.

First, the suspension of COND powdered graphite with Triton X100 detergent and about $100 \mathrm{ml}$ of water were added to the water glass to be stirred in a mixer for 1 minute. Subsequently, SMŠ 380 slag and 3 gradings of sand (PG1-3) were added. Finally, Lukosan $\mathrm{S}$ defoamer was added. The moulding being completed, the specimens were immersed into water. After 28 days, they were taken out to be kept in the open air for 7 days in order to stabilize their water content. Subsequently, the specimens were dried up at a temperature of $105^{\circ} \mathrm{C}$ until a constant mass was reached.

Three test bodies of dimensions $40 \times 40 \times 160 \mathrm{~mm}$ from each of the fifteen mixtures were manufactured. The results obtained from each test body are compared with those of the reference specimen.

Table 1. Chemical composition of granulated blast-furnace slag (\%).

\begin{tabular}{|lllllllll|}
\hline $\mathrm{SiO}_{2}$ & $\mathrm{Al}_{2} \mathrm{O}_{3}$ & $\mathrm{Fe}_{2} \mathrm{O}_{3}$ & $\mathrm{CaO}$ & $\mathrm{MgO}$ & $\mathrm{K}_{2} \mathrm{O}$ & $\mathrm{Na}_{2} \mathrm{O}$ & $\mathrm{MnO}$ & $\mathrm{SO}_{3}$ \\
\hline 39.75 & 6.61 & 0.46 & 39.03 & 10.45 & 0.63 & 0.38 & 0.37 & 0.71 \\
\hline
\end{tabular}

Table 2. Mixture composition.

\begin{tabular}{|c|c|c|c|c|c|c|c|}
\hline Mixture & $\begin{array}{c}\text { Slag } \\
{[\mathrm{g}]}\end{array}$ & $\begin{array}{c}\text { Water } \\
\text { glass } \\
{[\mathrm{g}]}\end{array}$ & $\begin{array}{c}\text { Sand } \\
{[\mathrm{g}]}\end{array}$ & $\begin{array}{c}\text { Graphite } \\
{[\mathrm{g}]}\end{array}$ & $\begin{array}{c}\text { Triton } \\
\text { X-100 } \\
{[\mathrm{ml}]}\end{array}$ & $\begin{array}{c}\text { Lukosan } \mathbf{S} \\
{[\mathrm{ml}]}\end{array}$ & $\begin{array}{c}\text { Water } \\
{[\mathrm{ml}]}\end{array}$ \\
\hline G0 & & & & 0 & 0 & 0 & 185 \\
\hline G1 & & & & 4.5 & 30 & 5 & 150 \\
\hline G2 & & & & 9 & 30 & 5 & 155 \\
\hline G3 & & & & 13.5 & 30 & 5 & 160 \\
\hline G4 & & & & 18 & 30 & 5 & 165 \\
\hline G5 & & & & 22.5 & 60 & 10 & 135 \\
\hline G6 & & & & 27 & 60 & 10 & 140 \\
\hline G7 & 450 & 90 & 1350 & 31.5 & 90 & 15 & 110 \\
\hline G8 & & & & 36 & 90 & 15 & 115 \\
\hline G9 & & & & 40.5 & 120 & 20 & 85 \\
\hline G10 & & & & 45 & 120 & 20 & 90 \\
\hline G15 & & & & 67.5 & 180 & 30 & 75 \\
\hline G20 & & & & 90 & 240 & 40 & 70 \\
\hline G25 & & & & 112.5 & 300 & 40 & 70 \\
\hline G30 & & & & 135 & 390 & 40 & 70 \\
\hline
\end{tabular}

The bodies to be tested (Table 2) were characterized by means of the impedance spectroscopy method [6]. The specimens were measured in the frequency range from $40 \mathrm{~Hz}$ to $1 \mathrm{MHz}$. An R\&S ZNC vector analyser with DAK12 coaxial probe (made by Speag) was used to measure at higher frequencies (from $100 \mathrm{MHz}$ to $3 \mathrm{GHz}$ ). The electrical conductivity $\sigma$ was measured within this frequency range.

Micro-images of alkali-activated slag mortars were taken at TESCAN MIRA3 XMU by means of a scanning electron microscope in the SEM mode. The experiments were carried 
out on dry specimens, the surface of which was coated with dust gold using an accelerating voltage of $20 \mathrm{kV}$.

\section{Results}

Electrical properties have been measured in two frequency bands of the high-frequency electric field.

Fig. 1 shows the specimen electrical resistance vs. frequency plot within the frequency range from $40 \mathrm{~Hz}$ to $1 \mathrm{MHz}$ with graphite powder content as a parameter. The electric resistivity decreases when the graphite amount and the electric field frequency increase. However, there is quite a distinct peak, which is located on the reference mixture curve (G0) at a frequency of about $1 \mathrm{kHz}$. A tiny peak can be observed at this frequency for the mixture, which was enriched by adding $1 \%$ of graphite. Only a monotonous decrease of the electric resistivity without any pronounced anomalies is observed when higher graphite amounts are added. The resistivity of the composites, which contain higher amounts of the powdered graphite, reaches its minimum value at relatively low frequencies below $10 \mathrm{kHz}$. The electric resistivity of all tested specimens decreased to a similar level above $100 \mathrm{kHz}$. To analyse the influence of the added graphite amount, a reference frequency of $1 \mathrm{kHz}$ was chosen (at this frequency, highest differences in the resistivity are observed).

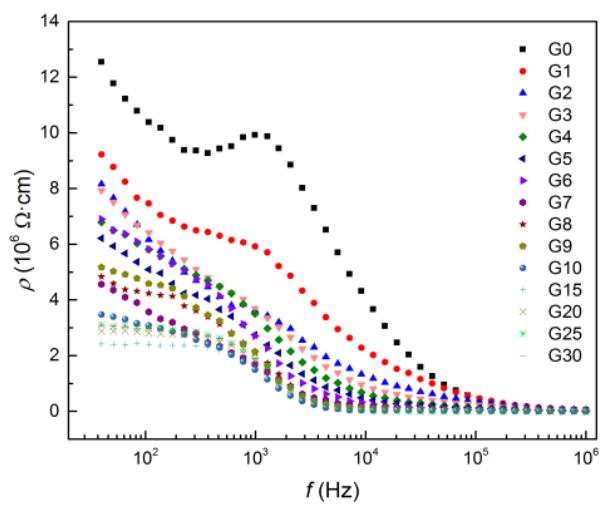

Fig. 1. Electric resistivity of AAS composites with 0 to $30 \%$ of powdered graphite in the frequency range from $40 \mathrm{~Hz}$ to $1 \mathrm{MHz}$ (the frequency is plotted in log scale).

Fig. 2a shows that even a small amount of added graphite reduces the electric resistivity substantially. The electric resistivity decreases when the amount of the filling substance (graphite) is growing. Its most effective value in terms of the graphite amount to the electric resistance ratio is reached at $10 \%$ of graphite. Such an amount of graphite may be supposed to be sufficiently high for ensuring contact between adjacent particles and, therefore, appears to be the best suited from the electric resistance (conductivity) viewpoint. It may therefore be stated that a higher graphite content than $10 \%$ influences the electric resistance of AAS composites to a lesser extent in the low and medium frequency range.

Fig. 2 illustrates the electrical conductivity vs. graphite content plot for six different frequencies of the electric field, namely, $0.5 \mathrm{GHz}, 1 \mathrm{GHz}, 1.5 \mathrm{GHz}, 2 \mathrm{GHz}, 2.5 \mathrm{GHz}$ and $3 \mathrm{GHz}$. The mixture containing $10 \%$ of graphite features a substantial growth of the electric conductivity for all selected frequencies of the electric field. An electric conductivity limit is evident to occur at lower frequencies $(0.5 \mathrm{GHz}, 1 \mathrm{GHz}$ and $1.5 \mathrm{GHz})$ for at least $25 \%$ of graphite added. At other frequencies, a steady growth of the electrical conductivity is 
observed irrespective of the graphite content (corresponding, for example, to a G30 mixture with $30 \%$ of graphite). Generally, the steepest growth of the electrical conductivity is observed below and up to $10 \%$ of added graphite. The growth is slower for higher graphite percentage. Electric conductivity versus frequency relationship is clearly evident here. The most noticeable differences can be observed at a frequency of $3 \mathrm{GHz}$ and the powdered graphite content of $30 \%$. The higher the electric field frequency the higher value of the electric conductivity is reached for $30 \%$ graphite specimens.
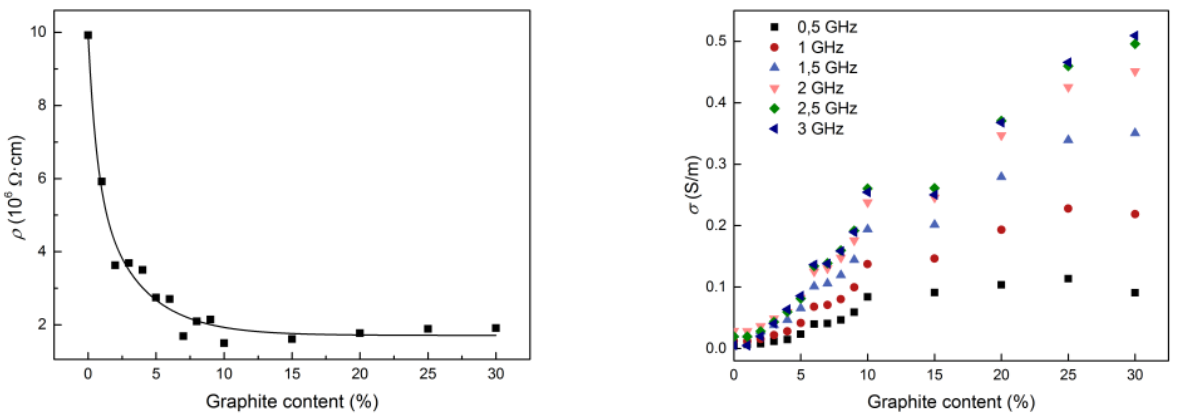

Fig. 2. a) Change in electric resistivity of AAS composites versus the graphite content at $1 \mathrm{kHz}$; b) electrical conductivity of AAS composites with $0-30 \%$ of graphite powder at different frequencies.

Fig. $3 \mathrm{a}, 3 \mathrm{~b}$ and $4 \mathrm{a}$ show the morphology of the fracture surface of AAS composites with conducting filling substance. Graphite particles in the form of relatively thin slabs with lamellar structure are clearly visible (Fig. 4b). In view of the fact that in this case these particles are sparsely dispersed (the AAS matrix contains only $5 \%$ of graphite), only few graphite particles can be seen here. Amorphous structure, which is prevailingly seen in the microscopic image, corresponds to the alkali-activated slag that is predominating here (Fig. 3a). Gradual increase of the graphite amount results in the particle denser packing, which in turn enhances the electric conductivity. After 3\% of the powdered graphite is added, the graphite will occupy about $50 \%$ of the matrix volume and the particles will be in close contact with each other (Fig. 4a). Such an amount enables the contact conductivity of the AAS matrix, the graphite internal resistance becoming the limiting factor. We would like to thank Dr Patrik Bayer for microscopic measurements (SEM - Scanning Electron Microscope).
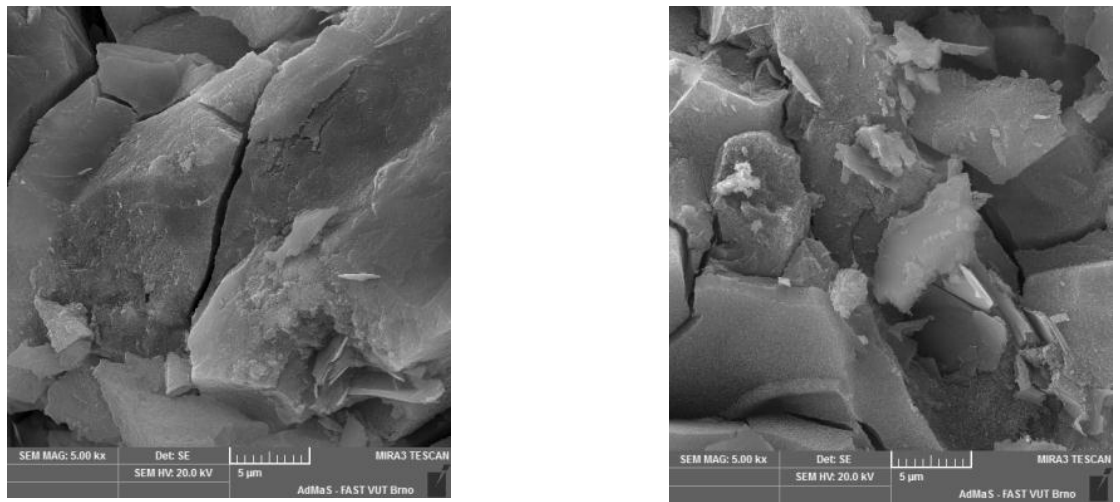

Fig. 3. a) Microstructure of AAS composites with $5 \%$ of graphite; b) $10 \%$ of graphite. 

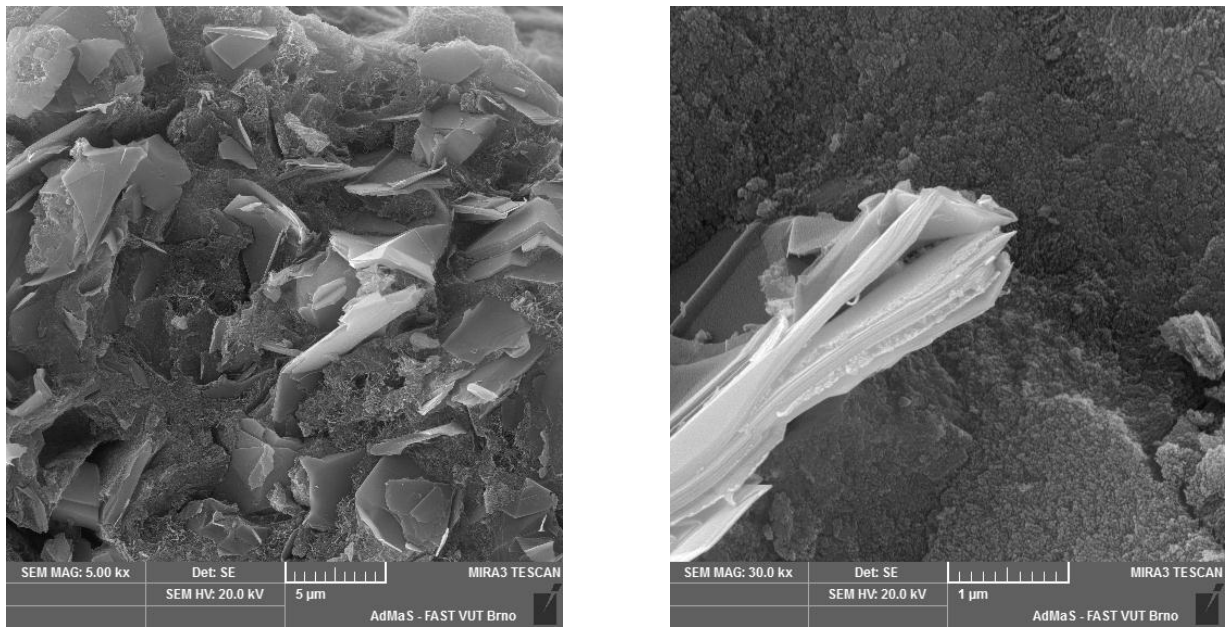

Fig. 4. a) Microstructure of AAS composites with $30 \%$ of graphite; b) lamellar structure of graphite particles.

\section{Conclusion}

The present paper deals with the change of electric parameters of alkali-activated slag mortars to which powdered graphite has been added. This graphite admixture improves the electric conductivity of the materials in question, making them easier to measure by electromagnetic-principle-based methods. An ideal graphite admixture is described from the viewpoint of both its amount and the most effective increase of the electrical conductivity. Another quantity to study was the electric resistivity and its frequency dependence. The micro-structure of the AAS composites with conducting filling substance has also been analysed by means of a scanning electron microscope.

This paper has been worked out under the project GAČR No. 16-02261S and under the project No.S-16-2967 supported by Faculty of Civil Engineering BUT.

\section{References}

1. R. Zhao, J. G. Sanjayan, Mag. Concrete Res. 63, 163 (2011)

2. F. Puertas et al., J. Eur Ceram. Soc. 31, 2043 (2011)

3. A. Fernandez-Jimenez: Cement Concrete Res. 29, 1313 (1999)

4. S. Matsutani, Y. Shimosako, Y. Wang, Physica A. 391, 5802 (2012)

5. K. Y. Kim, T. S. Zun, K. P. Park, Cement Concrete Res. 50, 34 (2013)

6. I. Kusak; M. Lunak, P. Schauer, Appl. Mech. Mater. 248, 370 (2013) 